\title{
A Brief Study of the Development and Application of "Internet+" in Middle School English Teaching
}

\author{
LIU Shi-chuan \\ Sichuan University of Arts and Science, Dazhou, China
}

\begin{abstract}
Internet education has appeared with the development of the Internet. Since "Internet+" has come up with in the 2015 government work report, it has become a hot word. "Internet+" has been applied to traditional education, which has reformed the traditional English teaching in middle school. Nowadays, there are many applications in teaching, such as distance education, smart classroom, and so on. Moreover, with the popularizing of big data, it provides all kinds of information for teachers and students in time, helping teachers in middle school to master the process of study among students. Also, parents can know their children's performance in school through the big data. In education, the development of the Internet has gone through a few parts from the lowest applications to the complex applications. The applications in education are gradually accepted by every educator. There is no limit of time and space so that people can study anywhere, any time.
\end{abstract}

Keywords: Internet + , the Internet and education, middle school English teaching, development, application, big data

\section{Introduction}

In the 2015 government work report, it was Prime Minister LI Ke-qiang that came up with the "Internet+" program, which was written into the government work report. As our action plan, it plays a very important role in our modern society, especially in our education. All of us have been deeply influenced by traditional education. The Internet has stepped into our modern life now. With the rapid development of our economy, the traditional education seems not to be fit for the development of a school. It is rather necessary for us to get an opportunity to reform the traditional education. Obviously, it all ringed upon the "Internet+". "Internet+" is a big trend in our society so that there is no chance for us to avoid it, especially when we are in the time of the Internet. The whole society is connected by the Internet at a very high speed. What is more, "Internet + ' is the new form that the Internet develops in the innovation 2.0 Era. Moreover, the core of "Internet + " is not the Internet, but the "+", which means combination" (JIA, 2015, p. 14). That is, it is the combination between "Internet+" and all kinds of traditional industries. In the past 10 years, the development of the Internet has been beyond our imagination.

According to Eric's Chinese online education's developing report in 2013-2014, it showed the scale of online education market in 2013 reached 83.97 billion RMB, and the growth rate was 19.9 percent, predicting it would reach 99.8 billion RMB in 2014, and the growth rate was 18.9 percent. (LI, 2015, p. 70)

LIU Shi-chuan, lecturer, M.A., School of Foreign Languages, Sichuan University of Arts and Science. 
In America, there are 1.34 million students majoring in degree or diploma course among 1.66 million students receiving online education. In a word, the development of the Internet education has a large market potentiality.

Nowadays, we can see that there are a large variety of productions that the Internet forms, such as the network media, network games, and e-commerce, etc. Taking an example of e-commerce, there are many shopkeepers who have their own shops. With the fast development of our economic and technology, the Internet is widely used by people. So, there is no doubt that the e-commerce comes into our view. All these new productions have a great impact on traditional industries. As for the Internet education, it can date back to many years ago in Britain. In 1969, the first opening university in the world was set up in Britain. This university was the mark of distance education in Britain. However, nowadays, America is the largest scale about the distance education. According to the statistics, the number of people who used iPad for study exceeded 35 million people and increased to 46 percent. It clearly showed that there were many people who used the iPad for study. With so many users increasing, our traditional education pattern is gradually changed.

\section{The Traditional Education Situation in English Teaching}

In the past 30 years, the English teaching in middle school has gone steadily developed, and has achieved giant development in many aspects, for example, there are a lot of policies that are beneficial to English teaching. At the same time, a large quantity of references and some other policies are published. More and more people realize the importance of English. There is good atmosphere for students to study. However, there are still some problems about traditional English teaching in middle school. There is often just a piece of chalk, a classroom, and one teacher. Students always have lessons according to the textbook. There are less resources or interests in classroom. As the Internet develops well, the traditional education in English teaching needs reform and innovation.

Under the time of "Internet+", the traditional teaching form in middle school seems to have many problems, which is unfit for the demand of social development. Traditional education is also called exam-oriented education. Although it can select a part of excellent talents, this idea about selecting talents as one result of exam still has some drawbacks. Indeed, more and more people are cultivated as the examination machine, and they just need to finish the paper perfectly. It is evident that this old form is not suitable for the growth of students. In our traditional English teaching, the problem is that teaching forms and ways are very single. According to the textbook, English teachers in middle school just teach the new words and relevant grammars about the words at first, and then get back to the contents to explain them. Even if there are activities, the teaching method is still too single. The teacher stands in the front of classroom and imparts basic knowledge to students. Besides, in traditional school, sharing teaching resources is very hard to achieve. Therefore, in English teaching, students just know the knowledge in the textbook. Moreover, most students have their own characteristics in middle school. They have different understanding about the things in different learning levels. Traditional English teaching will not easily fit and satisfy the student's demand. Another important problem is that traditional English teaching is restricted by time and space, which is not beneficial to the people who are working without more leisure time. Moreover, it is not good for the realization of life-long education. The most important problem is that the teacher emphasizes more on the theories than practice and pays more attention to knowledge than skills, which makes 
students have low practical ability and cannot adapt them to the society well. Therefore, in middle school, so many students are good at exam and work that teachers sign, but they cannot put English into practice so that they have poor spoken English. It is of necessity for us to find an innovative form of education that satisfies the needs of high development of a society. We should make full of the Internet and have innovative minds, making them to have a giant exertion.

\section{The Development and Applications of the "Internet+" in the Secondary English Classroom}

Confronted with the sharp development of economy, subsequently, the Internet also gets enormous development. Nowadays, the Internet has been introduced into the secondary English classroom.

"Internet + " has a very far-reaching influence on all aspects of life, as Prime Minister LI Ke-qiang has come up with this innovative idea these years. The Internet has been applied in our life. We can deeply feel that education has gotten giant change due to the application of the Internet, which changes the traditional forms of education in English teaching. The associate professor MENG Fan-hua of Capital Normal University expressed, “'Internet+ education' will change education, but not overturn it, even the current system in school” (DOU, 2015, p. 49). "Internet + " is just fully making use of the good side of education, and abandoning the bad side of education, combining the Internet with traditional education, and creating a new form of English teaching in middle school. "+" aimed at the combination between them. Paying more attention to the Internet that we daily contact, we find it will bring us a lot of developing opportunities, especially for the traditional industries. Compared with traditional industries, the new forms that the Internet leads to show us symmetrical information, a variety of industrial chains, and the industrial structure of low-cost, that is the advantages of the Internet. The Internet in essence can be regarded as a platform. People, information, and goods can be connected by low cost, and we are all familiar with Jingdong, Taobao, and other e-commerce, which connects consumers with goods. These are the productions of "Internet+". It recreated the traditional business through the Internet. It is well-known that we can get the goods in a shop and pay for the things to the seller. This activity can be regarded as traditional business. However, as the "Internet + " develops in our society, the e-commerce came into being. There is no necessity for us to pay for the goods face to face. Paying for money online is a simple and convenient way for these people who are busy with their work. There are many social platforms, such as Facebook, Micro-blog and We-chat, which combine one with another person in the Internet. Nowadays, there are many things that are involved through the Internet, which makes all the elements in our life to form interconnecting network. With the time of the Internet coming, a giant change has happened in all aspects of life. The Internet has made our earth into a "little village", and there are no obstacles for us to send and receive information. We can communicate with other people timely and get informed of the world through the use of mobile and the Internet. Nowadays, a large variety of educational investors and experts have focused on the Internet education. Moreover, it has formed a rudiment in education field in temporary time. MOOCS (Massive open online course), diverted classroom and distance education are productions under the time of the Internet, which have developed and been applied to our education and have a great influence on our teaching. Some researchers have to do some study about it and get a marvelous achievement. It is believed that online education will have a bright prospect. However, "Internet+ education" brings people convenience and other benefits, but it still has some defects in education, because the whole environment of the development of the Internet is not very good. In order to obtain 
some profits, someone will do harmful things to other people. Besides, due to lack of relevant supervising and varying quality in total level, teachers have the difficulty in assessing the effect of teaching, besides, the brand and service reputation have not been formed. Therefore, there is a long way. It is believed that the Internet education will have a further bright future.

\section{The Development of the "Internet + " in the Secondary English Classroom}

In the earlier middle English class, it is very common that the Internet has been widely used by the teacher, and especially in the urban area, English teachers use a lot of course-wares downloaded from the Internet as the teaching resources in classroom, which saves a great deal of time for teachers. Not only is it convenient, but also it arouses students' interests for study. Students will be more careful when the knowledge is showed by the PPT, which is more interesting on the screen than in the book. Usually, teachers will choose some interesting pictures as the background. Besides, sometimes, there are some relevant short movies and music to motivate students to study. Moreover, many course-wares have appeared in this time. Teachers can teach around the course-wares that are gained from the Internet in the class. Especially, when we have English classes, some teachers will show us a short video, which largely stimulates student's interests. After the video, they usually ask some questions to answer. It is a rather efficient way that can enforce the knowledge that they have learnt. There are still a lot of other complex applications except PPTs and videos. Recently, barrage teaching has come into being in Huazhong University of Science and Technology. It is the model that students listen to what teachers teach, and then students send message on the screen through the Internet and discuss questions on the Internet. Although students need to press the button, it may divert their attention. But at least they use phones for study, and their concentration is focused on study, which promotes interaction in class. From the simple applications to the complicated applications, the Internet has achieved giant development in English class. The teachers who lived in the rural and urban areas expressed: "the excellent teaching resources in urban can be shared with students in the rural through the Internet, which can shorten the distance, and even achieve the fairness in education" (XIA, 2015, p. 1). Indeed, the development of the Internet makes students enjoy better resources. Students, in middle school, can enjoy more resources about reading, listening, and so on. But, there is no doubt that hidden danger and defects of the Internet are there.

\section{The Applications of the "Internet+" in the Secondary English Classroom}

A lot of applications of "Internet+" have come into being, which change the traditional English teaching. As a teaching tool, it plays an important role in education, especially its applications in English teaching. There is a simple book with some vocabularies, short conversations, and short passages, which is not enough for students to study and put it into practice. But nowadays, more interesting contexts, pictures, and videos have appeared, which are beneficial to students. Moreover, more applications that are good for study come into being, such as distance education, smart classroom, and online to offline, which are being applied into the English class in middle school.

Distance education. Distance education is also called online education. Online education based on the era refers to learning experience or educational materials delivering primarily via the Internet to learners at a remote location. "This mode of learning may give learners the opportunity to work course materials at their own convenience or work collaboratively on class projects using tools, such as e-mail and discussion board" (ZHAO, 
2013, p. 142). Nowadays, distance education has been widely used in big cities where there is advance equipment. "The main characteristic of distance education is the communication at real time or virtual time between teachers and students across space, which is also the notable difference and advantage" (PAN, 2008, p. 15). In the remote rural area, students can accept some videos about listening or other resources from the excellent schools when they have an English class. It is impossible that you can have classes at anywhere, and even any time. It requires students to have these basic skills, such as the ability of self-learning, determined will. Learners study through distance education, which means there is no classroom, even no class's atmosphere. Students inevitably have difficulties in studying. Higher education can be learned by all kinds of people. Distance education has become an important form. People receive further education and have life-long study, which is beneficial to the idea that it is never too old to learn.

Smart classroom. Smart class, as a new form of digital and future classroom, will change our traditional class that focuses on the teachers. Nowadays, interactive teaching, focusing on students, has been formed. The modernized smart devices, such as whiteboard, projector, and 3D projection, etc., combine with the Internet. It connects students with teachers, and even parents, so that they can interact with each other, especially the current Ban Ban Tong, and it connects several or more classes together so that they can share one teacher and communicate with each other, and it changes traditional forms of teaching. Interactive whiteboard replaced the traditional blackboard, which achieved more effective interacting teaching. Moreover, teachers can timely share the teaching contents to student's computer through all the smart devices. It is very convenient for students to timely interact with teachers and send message to the class, and it is beneficial to teachers to master the situation about their study and give further induct. Nowadays, there are many places where experts have made some experiments about the smart classroom. It upgrades the teaching effect and exercises student's self-learning. The Flipped Classroom is another form of smart class. The novelty is that students can study the words, grammars, and other new knowledge through the teaching videos in middle school. Instead, they do exercises and discuss them in the class. This adverse teaching mode is just the Flipped Classroom, which is utterly different from the traditional teaching forms in the Middle English classroom. "It achieved this teaching goal: it's not about telling him a theory, but about teaching him how to find a theory" (MA, 2015, p. 78). The Flipped Classroom makes students voluntarily study knowledge through the electrical devices and master it or even put it into practice. That is the smart class, which makes teaching procedure easier and more effective.

Online to offline. Online to offline is also called off-line business model, referring to sale purchase or order on line drive running consumption off-line. Its application in education is not only limited in recruiting students online, but also widely expanded into teaching's field. As the professional education platform of online to offline, it connects the majority of education institutions or managers so that they can discuss and operate it together. Nowadays, there are 11 educational institutes in China that have been marketed in the overseas. In middle school, the practice of the diverted classroom is the exploration of online to offline. In its classroom, this form has been changed, and it is finished by imparting knowledge with the help of the assistant of information technology after class, and absorbing the knowledge with the help of teachers and students, which is the diverted classroom. Nowadays, "the crazy teacher" is on the market in Changsha, and it is a platform that is based on the O2O of mobile Internet and information service outside the school. Parents and students can choose the teachers online and get teaching service offline. But, online to offline is not so perfect, and it still has some defects. There are no 
series of study's plans, that is, there is no good leader so that students are easy to get lost. Besides, there is no sense of belonging, which is beneficial to the development of online to offline.

Ecological pattern of wisdom education. Nowadays, an ever-increasing number of people come to realize the importance of ecological teaching. Therefore, this new model has been developed. It advocates that we should use our education cloud and try our best to diminish the use of paper by using electrical devices, such as tablet PC in our traditional English classroom of middle school, and it requires more exam paper and other reference sources with little knowledge of the textbook. Therefore, through the latest development effect, we can largely reduce the use of paper. Students can use tablet PC or mobile phone as a study tool. Moreover, teachers can download resources from the electric devices and project them into the interactive whiteboard, which cannot only save paper, but also make students have more abundant resources to study. It is rather common that there are the interactive whiteboards in the classroom, especially in the train school. Our environment can get protection. It is not only in that aspect, but also in the aspect of respecting humanity. Our education needs to focus on the people and pursue to keep in harmony between human beings and the nature. As teachers, they must have the responsibility of making students to feel the value of life in the class. Taking the Dulangkou Middle School as an example, its main idea is focused on students, aiming to find every student's interest, gift, and specialty and give them a right guide for their development. So, trying to build an ecological class is teachers' task. It is said that educators try to pay more attention to innovation and self-learning, not the task. Building a harmonious and ecological English class makes the students control the class, for they are main bodies in class. Ecological pattern of wisdom education mainly changes the traditional class, making students in middle school enjoy themselves and have fun in class.

Education cloud + big data. The time of big data is approaching, the big data is more important through the education cloud, and it is gradually applied to education. The big data in education is hierarchical, such as student level, classroom level, teacher level, etc. Only if we master these data in different hierarchy can we provide relevant data for them. In middle school English teaching, big data can analyze every individual and the whole process of study in a class, and respond to the condition of study and the periodical effect of study so that the teachers can find the problem about study and govern the process of study. It is said that Big English is a good example in applying big data into English teaching. The accomplishment and popularizing of the technology of big data plays a critical role in promoting the development of "Internet+". It provides some data information for the educators and helps to form a scientific strategic decision. Students study with the mobile phone, iPad, and other electrical devices, therefore, there is much information about their study producing every day. Through analyzing and sorting the information, big data makes it convenient and useful for teachers, students, and parents. In the Brooking Institution Report, American dependently study institution said: "big data made it possible to ascertain the information about students' behavior and the method of study, not depending on periodical test expression". Supervisor can analysis what students know and what is the most effective technology about every student. Through analyzing the focusing data, teachers can use more subtle ways to research the condition of study. Big data serves students, providing more exercises that they did before or have spent double time finishing, to a large extent, which improved the efficiency of study. Also it serves parents, they can master the condition of children' study and do some relevant measures. Moreover, teachers can have effective classes by analyzing the data. Besides, all the data in all kinds of fields are shown by the education cloud, which is the first professional 
education platform that uses the Cloud Computing Technology. It provides the cloud services for the education, such as net space, and it can obtain the resources, and share the platform. The practical application of big data is not mature, which needs further development. It is believed that big data will be wider and penetrate into the field of education. Through the education cloud, big data can be a driver, which can analyze the process and effect of study, and further improve the methods and ways of teaching. We can really achieve the idea that improves effect of study and promotes self-learning.

\section{Conclusion}

The unit between the traditional education and the Internet has been an inevitable trend. "Internet+" makes fully use of its advantages. It is applied to English teaching. It gives rise to public's concern when "Internet+" has been come up with and developed. What is the Internet and education? It is said that the Internet and education is the smart education, which carries education into the platform of Internet. It combines the traditional education with the Internet education and makes use of the resources of traditional education and efficient platform of the Internet and education, so it can make them realize mutual compensation of advantages and achieve its sustainable development. "Internet+ education" pushed up the "wall" of school, making all kinds of online resources shared easily. Nowadays, it is widely used by many teaching institutions. There are many productions under the development of the Internet, such as distance education, MOOC, smart classroom, and big data. As these productions come into being, our traditional education has great change, and there is no longer one school, one classroom, even one teacher, but one net, one mobile terminal, and even hundreds of students, that is the Internet and education. "Internet + " makes use of the Internet and technology, reforming the traditional education, so the new form of education has appeared. From the earliest PPTs to modern applications, such as distance education, MOOC, etc., the development of the Internet almost has experienced two periods. There are no longer limited resources for us, and we can get many resources at anywhere or anytime. As for the Internet and education, its essence is a new education form. "We should know how to resort for the Internet and IT technology, effectively carry out teaching and study activities when the instructors and students are separated by distance or time" (LIN, 2015, p. 10). However, everything has its ups and downs. Nowadays, there are some rogue businessmen who did some low-quality resources and other things to damage the student's benefits in order to gain high profits. So the environment of the development of the Internet is not beneficial. Moreover, it pays more attention on Website Experience Service and Network promotion. As for the Internet and education, it lacks the learning atmosphere, so whether a person sticks to study or not, it is totally retorted for his will power. So, the system of the Internet education is not mature. However, with the system of the Internet and government's supervision improving and strengthening, it is believed that the Internet education has a further and bright future. Moreover, it must be a continuously developing process.

\section{References}

DOU, J. J. A. (2015). Tale of two worlds: Internet+ Education. Liaoning Education, 8, 49-51.

JIA, Y. X. (2015). Big date's application in the process of Internet+. Telecommunications Technology, 6, 14-15.

LI, C. P. (2015). Collide between traditional education and Internet education. E-Business Journal, 9, 70-71.

LIN, L. J. (2015). Internet+ education: World's elite school courses are available at home. Innovation Time, 7, 10-11.

MA, X. (2015). Analysis of the education's principles and sufferings of flipped classroom and Internet+ education. Course Education Research, 12, 78. 
PAN, J. (2008). The application of modern distance education in teaching and learning. Science \& Technology Information, 27, 11-17.

XIA, N. (2015). Internet+ education makes education much farer. Yuxi Times.

ZHAO, Y. (2013). On the instructor role in online education. Overseas English, 10, 142-145. 